\title{
Aerodynamic Performance and Acoustic Measurements of a High-Lift Propeller in an Isolated Configuration
}

\author{
Nikolas S. Zawodny, ${ }^{*}$ Henry H. Haskin, ${ }^{\dagger}$ and Douglas M. Nark ${ }^{\ddagger}$ \\ NASA Langley Research Center, Hampton, VA, 23681
}

\begin{abstract}
A series of aerodynamic performance and acoustic measurements has been made on a high-lift propeller intended for utilization on a distributed electric propulsion (DEP) aircraft. Tests were performed in the NASA Langley Low Speed Aeroacoustic Wind Tunnel (LSAWT), which has recently undergone a capability enhancement for the testing of small propellers/rotors and small unmanned aircraft system (UAS) platforms. The objectives of this testing campaign are two-fold: first to demonstrate the facility capabilities for performing small propeller aeroacoustic testing, and second to compare experimental measurements with computational fluid dynamic (CFD) predictions and CFD-based acoustic predictions of the tested propeller configurations for tool development and validation purposes.
\end{abstract}

\section{Nomenclature}

$c_{0} \quad$ Ambient speed of sound, $\mathrm{m} / \mathrm{s}$

$C_{P} \quad$ Propeller power coefficient, $P / \rho_{\infty} n^{3} D_{p}^{5}\left(=2 \pi C_{Q}\right)$

$C_{Q} \quad$ Propeller torque coefficient, $Q / \rho_{\infty} n^{2} D_{p}^{5}$

$C_{T} \quad$ Propeller thrust coefficient, $T / \rho_{\infty} n^{2} D_{p}^{4}$

$D_{b} \quad$ Nacelle body diameter, $\mathrm{m}$

$D_{\text {nozzle }} \quad$ Tunnel inlet diameter, $\mathrm{m}$

$D_{p} \quad$ Propeller diameter, $\mathrm{m}$

$J \quad$ Propeller advance ratio, $U_{\infty} / n D_{p}$

$L \quad$ Overall Sound Pressure Level (OASPL), dB

$M_{\infty} \quad$ Tunnel freestream Mach number, $U_{\infty} / c_{0}$

$N_{b} \quad$ Number of propeller blades

$n \quad$ Propeller rotation rate, revolutions per second

$U_{\infty} \quad$ Tunnel freestream velocity, $\mathrm{m} / \mathrm{s}$

$\bar{u} \quad$ Mean measured velocity, $\mathrm{m} / \mathrm{s}$

$\beta \quad$ Blade element twist angle (rel. plane of rotation), deg.

$\eta \quad$ Propeller efficiency coefficient, $C_{T} J / C_{P}$

$\rho_{\infty} \quad$ Ambient air density, $\mathrm{kg} / \mathrm{m}^{3}$

$\Omega \quad$ Propeller rotation rate, $\mathrm{RPM}$

$\theta_{o} \quad$ Geometric observer angle, deg.

$\theta_{C} \quad$ Shear layer-corrected observer angle, deg. Subscripts:

$c \quad$ Corrected rotation rate (for sea level, standard day conditions)

C Shear layer correction

$m \quad$ Mechanical rotation rate

$P \quad$ Periodic noise contribution

$B \quad$ Broadband noise contribution

*Research Aerospace Engineer, Aeroacoustics Branch, Member AIAA; nikolas.s.zawodny@nasa.gov

$\dagger^{\dagger}$ Facility Engineer, Aeroacoustics Branch, Member AIAA; henry.h.haskin@nasa.gov

¥Senior Research Scientist, Structural Acoustics Branch, AIAA Associate Fellow; douglas.m.nark@nasa.gov 


\section{Introduction}

Distributed electric propulsion (DEP) has become a very attractive, environmentally friendly option for future short-range civilian transports. The premise behind DEP vehicle flight is typically an array of "high-lift" propellers distributed along the leading edge of the aircraft wing (see Fig. 1). In this case, these propellers are designed to increase the dynamic pressure over the sections of the wing in the propeller slipstreams, thereby increasing the total lift on the wing. These high-lift propellers are intended to be utilized during the takeoff and approach flight conditions of the vehicle, while two additional wingtip-mounted propellers are utilized during cruise. NASA has been investigating the potential benefits of DEP technology as part of the Scalable Convergent Electric Propulsion Technology Operations Research (SCEPTOR) project. These investigations have included the development of flight demonstrator ground test $\operatorname{articles}^{1}{ }^{1}$ a thorough conceptual design and tradespace exploration of a proposed flight demonstration vehicle, ${ }^{2}$ and design and selection of a proposed high-lift propeller system configuration. ${ }^{3}$

Due to the novel nature of a high-lift propeller system for a DEP vehicle, it is important to experimentally ascertain the performance of the proposed propulsion system. This is because the nature of these propellers is a considerable departure from traditional thrust-generating propellers. The different operational purpose of these propellers challenges the capabilities of conventional propeller design tools. Furthermore, consideration of the radiated acoustics of these components is warranted due to their intended use during the takeoff and approach phases of the aircraft flight.

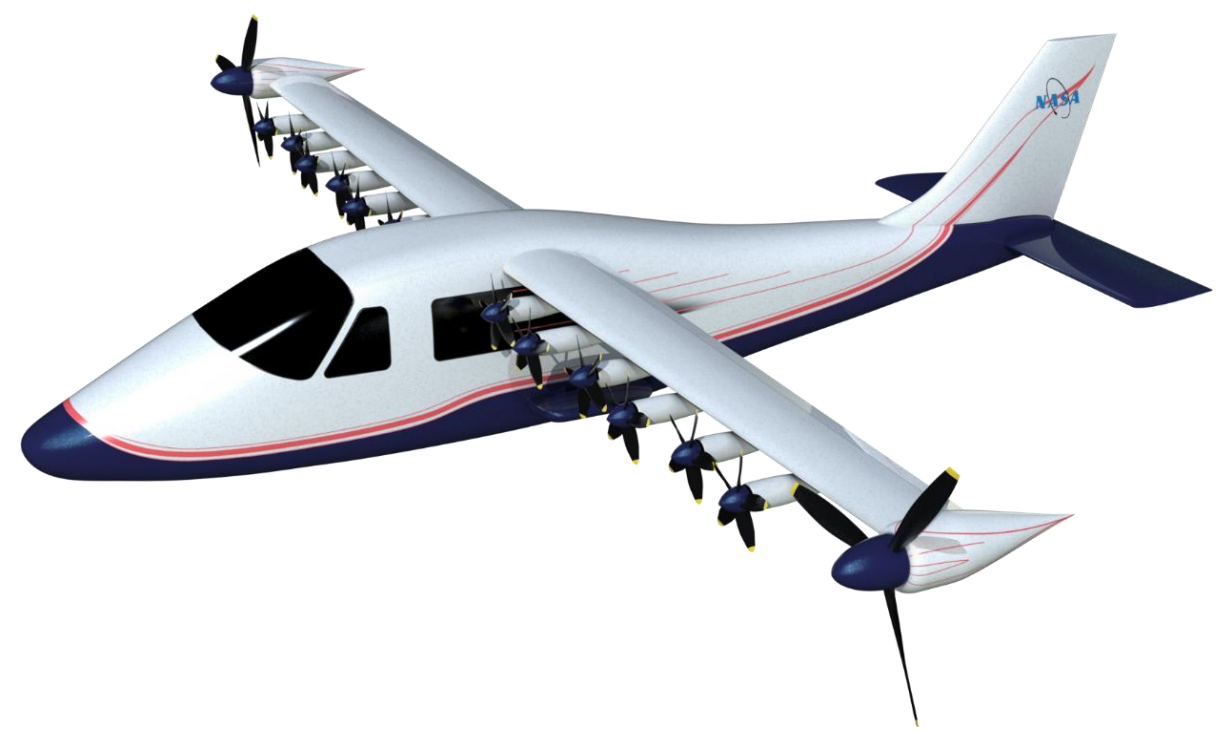

Figure 1. Rendering of SCEPTOR vehicle concept. ${ }^{2}$

\section{Technical Approach}

A testing campaign was developed for the purpose of acquiring both propeller aerodynamic performance and acoustic measurements over a range of flight conditions on a 5-bladed high-lift propeller concept. The following sections provide an overview of the facility, test conditions, test hardware, data acquisition, and prediction techniques utilized in this study.

\section{A. The LSAWT}

The NASA Langley Low Speed Aeroacoustic Wind Tunnel (LSAWT) has recently undergone a capability enhancement for the purposes of acquiring aerodynamic performance and acoustic data of small unmanned aircraft systems (sUAS) and small electric propeller/rotor platforms. ${ }^{4}$ The LSAWT is an open-circuit free 
jet wind tunnel that is currently configured for a freestream Mach number range of $0.045 \leq M_{\infty} \leq 0.140$; however, it has an upper end capability of $M_{\infty, \max }=0.32$. The test chamber is acoustically treated with an approximate cut-on frequency of $200 \mathrm{~Hz}$, and is outfitted with a 28-element linear array of 6.35 mm-diameter B\&K model 4939 free-field microphones. The test section length (from inlet trailing edge to flow collector leading edge) is approximately $5.6 \mathrm{~m}$, and the circular inlet nozzle diameter $D_{\text {nozzle }}$ is $1.93 \mathrm{~m}$. Respective mean flow and turbulent velocity surveys of the test section at $M_{\infty}=0.10$ have identified a core flow size of radius $r_{C} \approx 0.42 D_{\text {nozzle }}$ and a centerline turbulence intensity of $T I=0.054 \%$ at an axial location of $x / D=0.855$ downstream of the inlet nozzle trailing edge. ${ }^{4}$ The propellers tested in this study were positioned at an approximate downstream location of $x / D=0.645$ for all tests. A picture of the isolated propeller apparatus positioned within the LSAWT test section is provided in Fig. 2. The following section describes the primary components of the testing apparatus in more detail.

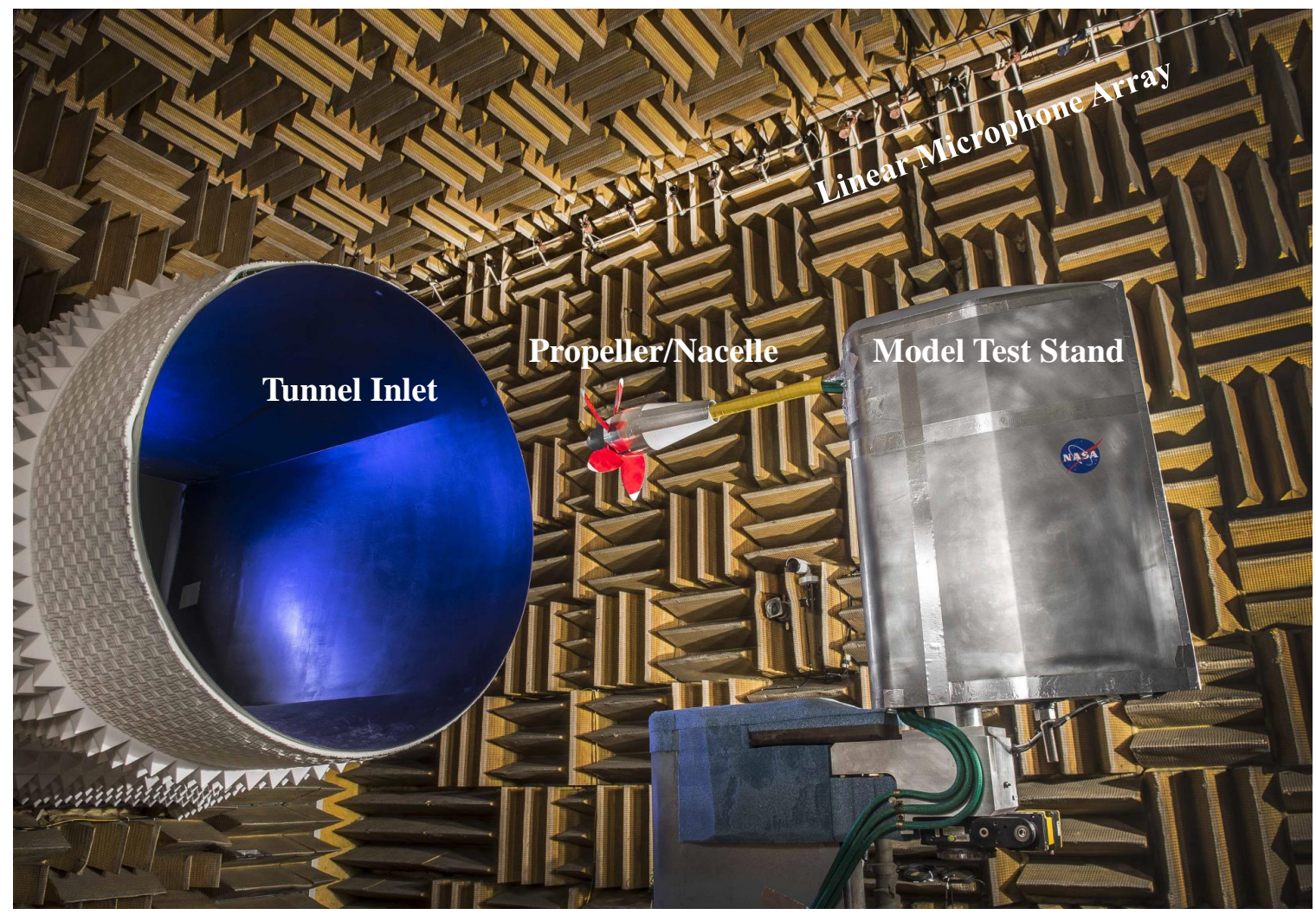

Figure 2. Isolated propeller testing apparatus installed within LSAWT test section. Note: 5-bladed high-lift propeller shown; flow is from left to right.

\section{B. Test Conditions}

Two different propeller designs were tested in this study: a 5-bladed propeller intended for high-lift (HL) operation on a DEP aircraft,,${ }^{5,6}$ and a 3-bladed conventional cruise (CC) propeller design intended for fixedwing aircraft operation. Images of these propellers installed in the LSAWT test section are provided in Fig. 3. Details of the propeller geometries and the wind tunnel test conditions are provided in Table 1. As this table shows, the high-lift propeller exhibits a relatively large reference chord (approximately 19\% of the propeller diameter) and pitch angle compared to the $\mathrm{CC}$ propeller. The range of tested freestream Mach numbers was intended to span the full flow speed capability of the LSAWT in the current tunnel configuration for a wide range of propeller advance ratios. Propeller performance and acoustic measurements were acquired over the advance ratio ranges indicated in Table 1 using 14 different tunnel freestream velocities, along with static conditions $\left(M_{\infty}=0\right)$, for all indicated propeller rotation rates. 


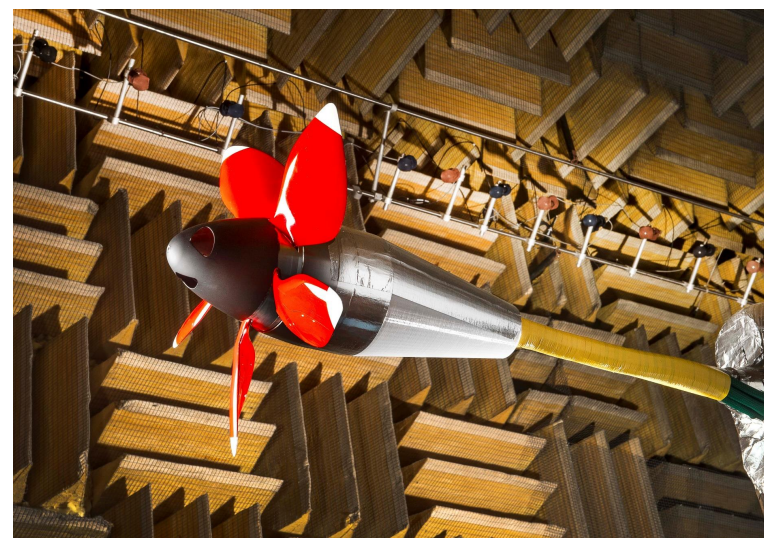

(a) 5-bladed HL propeller

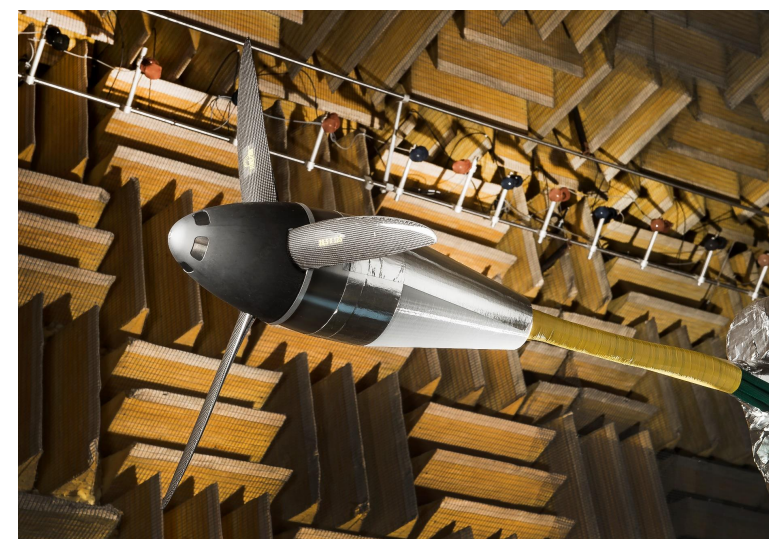

(b) 3-bladed CC propeller

Figure 3. Images of the two tested propellers.

Table 1. Propeller geometries and test conditions.

\begin{tabular}{|l|c|c|}
\hline Parameter & HL Propeller & CC Propeller \\
\hline$N_{b}$ & 5 & 3 \\
$D_{p}, \mathrm{~m}$ & 0.447 & 0.724 \\
Chord at $r / R=0.75$ & $0.191 D_{p}$ & $0.055 D_{p}$ \\
Pitch at $r / R=0.75$, deg. & 30.9 & 10.1 \\
\hline \hline$\Omega_{m}, \mathrm{RPM}$ & 3000,3600 & 3000,4000 \\
& 4000,4800 & 5000,6000 \\
& 6000,6600 & \\
Range of tested $M_{\infty}^{*}$ & $0.045-0.138$ & $0.045-0.138$ \\
Range of tested $J^{*}$ & $0.320-1.540$ & $0.212-0.879$ \\
\hline
\end{tabular}

* Static flow conditions $\left(M_{\infty}=0\right)$ also acquired for all indicated rotation rates.

\section{Test Hardware}

\section{Model Test Stand}

Test articles are mounted within the LSAWT test section on a mobile model test stand (MTS). The MTS is meant to accommodate a variety of testing platforms from electric propellers and small rotarywing UAS components to full sUAS vehicles. A visual component breakdown of the MTS is provided in Fig. 4. As this figure shows, the MTS is equipped with hardware which allows both pitch and yaw movements and which is housed within an airfoil fairing assembly. Test articles are mounted to the MTS on a sting arm.

\section{Propeller/Nacelle Assembly}

A close-up internal cut-away view of the propeller/nacelle assembly tested in this study is provided in Fig. 5. As this image shows, the propeller/nacelle assembly consists of a propeller pow-

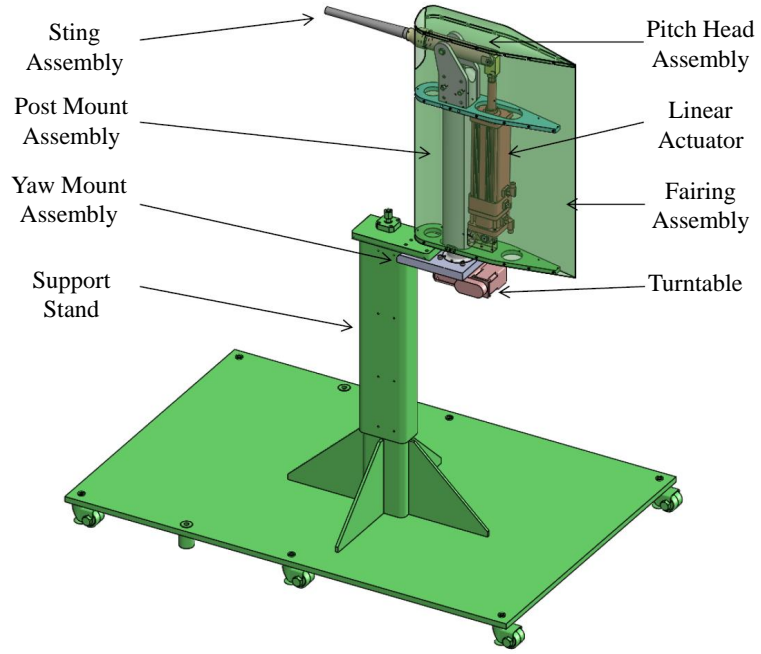

Figure 4. Components of the mobile model test stand. 
ered by an in-running brushless motor, which is mounted to the measurement stage of a six-component strain gage force balance. The leading edge of the propeller is faired with a conical spinner. The spinner shown in Fig. 5 consists of open ports to allow air ventilation through the motor assembly for cooling. A sealed spinner was also tested to identify loading and acoustic impacts of a vented spinner. A rapid-prototyped nacelle fairing was fabricated to match the outer diameter of the motor housing and to cover the length of the force balance. Great care was taken to ensure that electrical power and instrumentation wiring routed through the model did not come into contact with either the nacelle fairing or the balance.

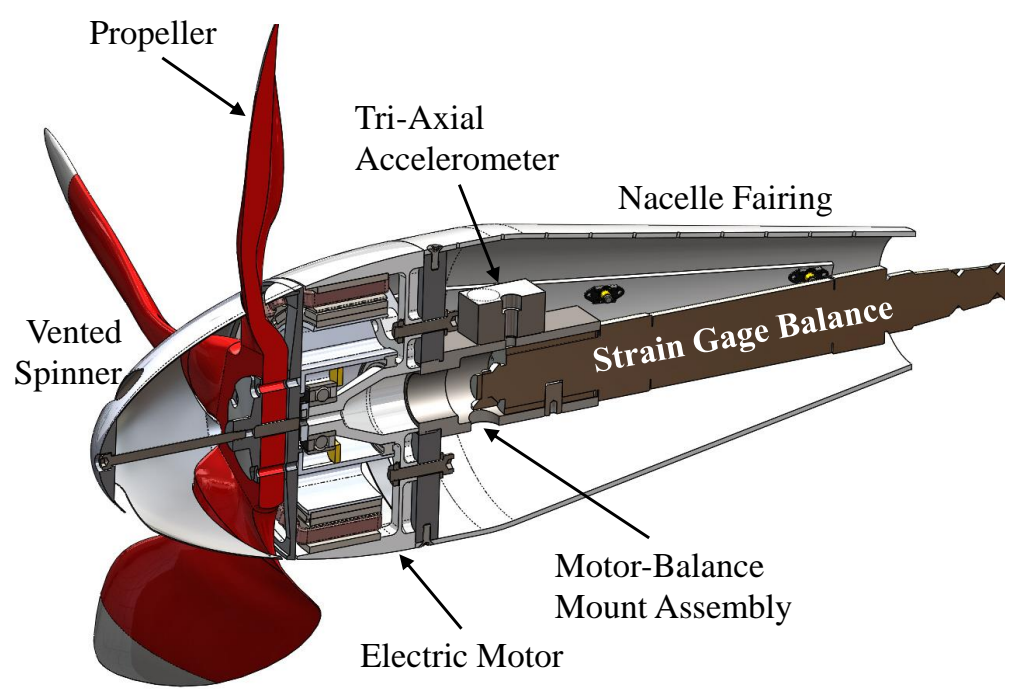

Figure 5. Cut-away view of the propeller/nacelle assembly.

\section{Power/Control System}

The propeller system is powered using a Magna-Power TS-series 25-kW (125V/200A) DC power supply coupled with an MGM-Compro HBC-series (120V/280A) 3-phase electronic speed controller (ESC) and a 20-pole in-running Joby JM-1 motor. Images of these components are provided in Fig. 6 . The power supply was utilized to provide a constant $100-\mathrm{V}$ supply to the ESC in a constant voltage mode of operation. The current draw commanded by the ESC was allowed to vary depending on the user-commanded rotation rate of the motor. A controller area network (CAN) bus issued commands to the ESC as well as monitored the operational state of the ESC and motor. Temperature of the motor was monitored through the CAN bus using three surface-mounted temperature probes positioned along the motor housing inner surface (see Fig. 6(c). To ensure safe motor operations, upper allowable current draw and motor surface temperature were limited to $140 \mathrm{~A}$ and $60^{\circ} \mathrm{C}\left(140^{\circ} \mathrm{F}\right)$, respectively.

\section{Data Acquisition and Post-processing}

Dynamic data were acquired on National Instruments ${ }^{\mathrm{TM}}$ PXI-6143 dynamic signal acquisition modules installed across two PXI-1045 chassis. Microphone data were acquired on one of the chassis at a sampling rate of $80 \mathrm{kHz}$. Balance, accelerometer, and motor temperature data were acquired on the second chassis at a lower sampling rate of $40 \mathrm{kHz}$. Microphone and propeller/motor performance data acquisitions were divided between these two chassis to allow for real-time monitoring of the performance data. Microphone data were bandpass-filtered between high- and low-pass cut-off frequencies of $80 \mathrm{~Hz}$ and $40 \mathrm{kHz}$, respectively. This filtering provided a usable flat passband (less than $-0.2 \mathrm{~dB}$ deviation) within a frequency range of 125 $\mathrm{Hz} \leq f \leq 25 \mathrm{kHz}$. Each wind tunnel run was acquired for a time duration of 12 seconds.

Acoustic data were post-processed using three different techniques: ${ }^{7,8}$

1. Random dataset: narrowband acoustic spectra computed using fast Fourier Transform (FFT) 


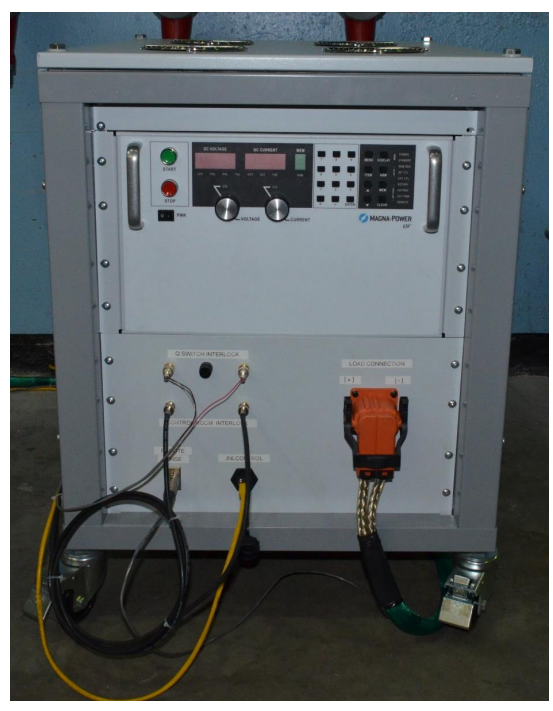

(a) 25-kW Power Supply

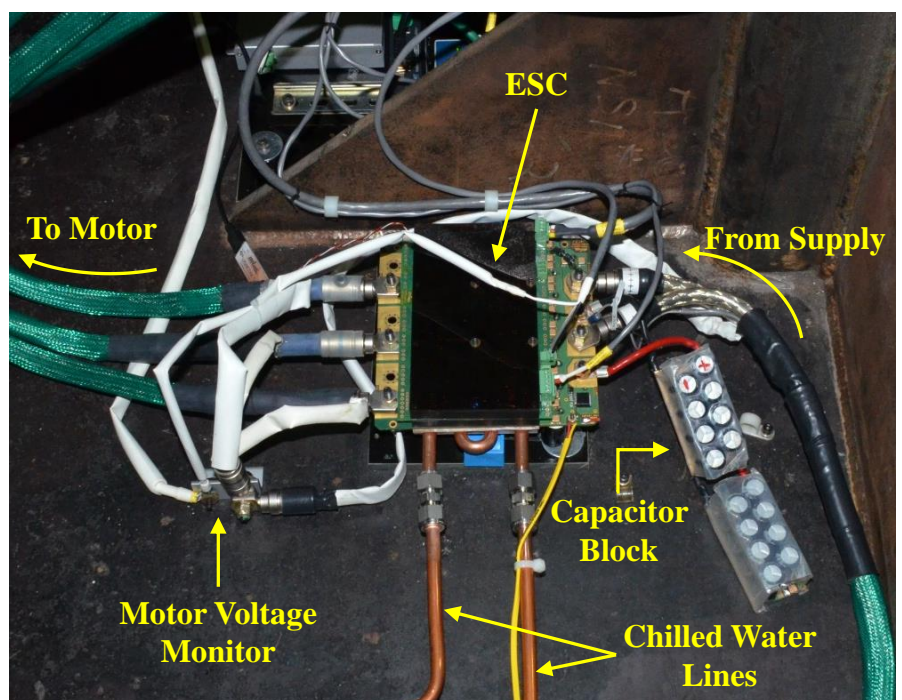

(b) Motor Controller

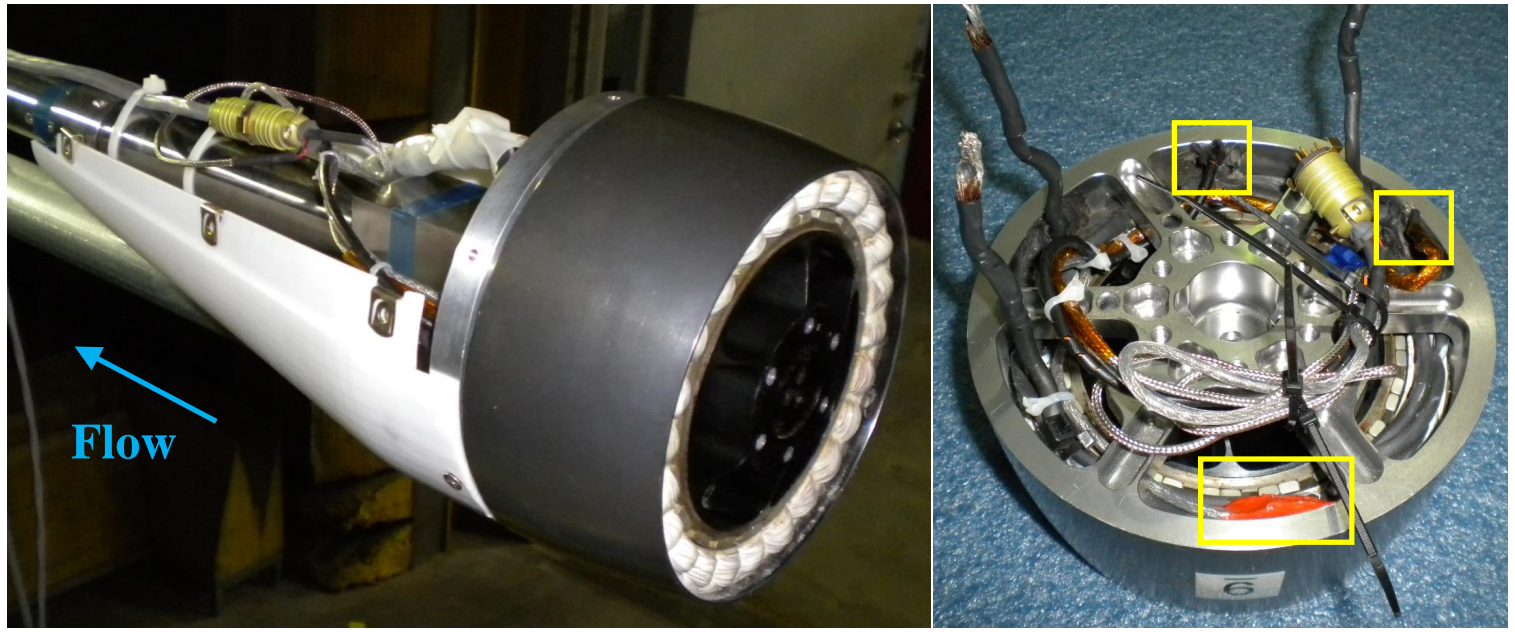

(c) Motor and Temperature Sensor Locations

Figure 6. Components of the propeller power and control system.

2. Unfiltered rotor revolution: Mean rotor revolution time history computed, subtracted from time record to retain random noise components

3. BPF harmonic-filtered data set: Acoustic time series filtered to retain only harmonics of BPF

The first (and simplest) of these techniques simply treats the acquired data as a random data set and computes narrowband acoustic spectra using the fast Fourier Transform (FFT). Acoustic spectra using this method were computed using a Hanning window with $75 \%$ overlap and a frequency resolution of $5 \mathrm{~Hz}$. For 12 seconds of data, this results in an autospectral random uncertainty of $\epsilon_{r}=9.0 \%$, which translates to a random SPL uncertainty of $u_{r, \mathrm{SPL}} \in\{-0.41,+0.37\} \mathrm{dB} .{ }^{9}$ Method 2 allows for the separation of periodic and random noise components in the time domain. Narrowband spectra are then computed on the mean revolution time history and residual random time series for a common frequency resolution of $5 \mathrm{~Hz}$. Processing the mean and residual time series with a common frequency resolution required replicating the mean revolution time history by the number of revolution time blocks. Finally, the purpose of method 3 is to more accurately compare acoustic amplitudes between predictions and experiment in the time domain. The reader is referred to Refs. 7,8 for more detail on the latter two processing techniques. 


\section{E. Prediction Techniques}

\section{OVERFLOW}

High-fidelity aerodynamic predictions are done using the NASA OVERFLOW code $^{10}$ (labeled OF2 in following figures and discussion). OVERFLOW is a multibody/moving body Navier-Stokes CFD code that utilizes overset structured grids to model the fluid volume. Acoustic predictions are then performed using the CFD-provided impermeable loading data on the propeller blade surfaces. These data are input into the PSU-WOPWOP code, which is a Ffowcs Williams and Hawkings (FW-H) solver. ${ }^{11}$ The simulated geometry includes five instances of the high-lift propeller blade design, a conical leading-edge spinner, and a "tear-

Table 2. Flight conditions of HL propeller CFD simulations.

\begin{tabular}{|cccc|}
\hline Case $\#$ & $M_{\infty}$ & $\Omega_{c}(\mathrm{RPM})$ & $J$ \\
\hline 1 & 0.000 & 5866 & 0.000 \\
2 & 0.059 & 5866 & 0.457 \\
3 & 0.092 & 5866 & 0.717 \\
4 & 0.118 & 5866 & 0.915 \\
5 & 0.123 & 4800 & 1.173 \\
6 & 0.132 & 4000 & 1.509 \\
\hline
\end{tabular}
drop" nacelle trailing-edge geometry (see Fig. 7(a)).

The simulations were performed over a range of advance ratio conditions to compare performance trends with experimental measurements. Table 2 details the simulated flight conditions that are considered in this paper. Note that all conditions considered in this paper are at a $0^{\circ}$ propeller angle of attack. Acoustic predictions were performed utilizing the surface pressure data on the propeller blade surfaces (see Fig. 7(b)). The spinner and nacelle are included in the CFD computations and have an effect on the propeller aerodynamics. However, these surfaces are not directly included in the acoustic predictions because, relative to the propeller blades, they are expected to have a negligible impact on the acoustics. The simulations were performed as part of Ref. 12, which can be referred to for more details of the simulation parameters. It is worth noting that CFD simulations were only performed on the HL propeller since it was the only one for which a high resolution surface mesh definition was available.

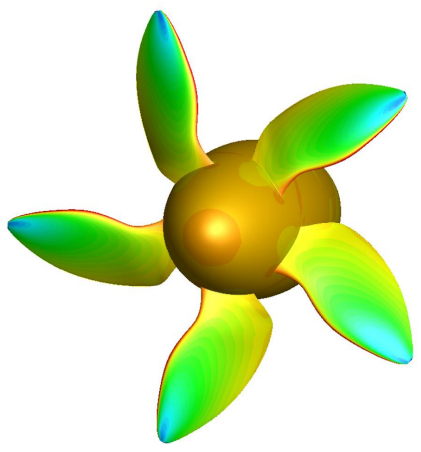

(a) CFD geometry of HL propeller design

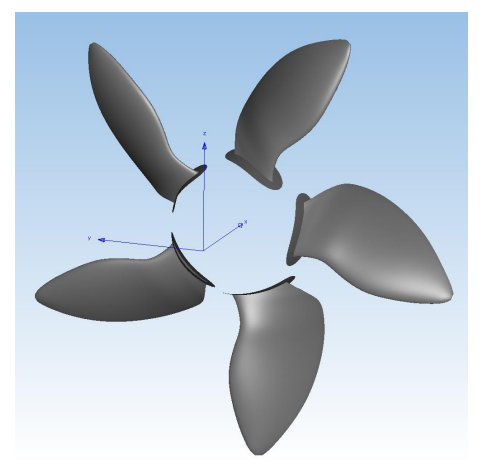

(b) Impermeable acoustic data surfaces

Figure 7. Visualization of HL propeller geometry surfaces used in aerodynamic and acoustic predictions. ${ }^{12}$

\section{Propeller Analysis System}

The NASA Aircraft NOise Prediction Program - Propeller Analysis System (ANOPP-PAS) utilizes blade element momentum theory (BEMT) to predict the aerodynamics, performance, and noise of subsonic propellers. ${ }^{13}$ The blade profile analysis modules of PAS include a coordinate transformation using a Joukowski transformation, potential flow around the blades computed by Theodorsen's method using the Kutta condition to fix circulation, and boundary layer analysis using the Holstein-Bohlen or Truckenbrodt methods for respective laminar and turbulent regions. Propeller performance and induced flow are then computed using Lock's method with the Prandtl circulation function for the blade tip region. Finally, a Subsonic Propeller Noise (SPN) module is utilized for computing acoustic pressure time histories and spectra at defined observer locations. This noise module is a direct implementation of Farassat's F1A FW-H acoustic solver ${ }^{14,15}$ While CFD analysis was only performed on the HL propeller geometry, PAS blade element analyses were able to be conducted on both tested propellers. 


\section{Results}

The results of this propeller study are divided into two primary sections: propeller performance trends and acoustics. The performance of the propellers is assessed through the nondimensional coefficients of thrust $\left(C_{T}\right)$, power $\left(C_{P}\right)$, and efficiency $(\eta)$. Comparisons with the CFD results are also performed.

\section{A. Propeller Performance Trends}

A summary of the propeller performance data is provided in Fig. 8 along with comparisons to the HL propeller CFD simulation results reported in Ref. 12. The experimental data are plotted as sets of variable advance ratio conditions for a common rotation rate. This is done in order to identify any variations in performance trends that could be attributed to Reynolds number effects and/or blade deflections. The error bars that accompany the experimental data points represent a root-sum-squares (RSS) calculation using the full-scale measurement uncertainty (bias error) of the strain gage balance measurements. The error bars are therefore larger for lower rotation rate cases due to the nondimensionalization of the performance values by the appropriate power of the rotation rate. There is also the general trend of increasing uncertainties in $\eta$ as a function of advance ratio, $J$, due to the coupling of uncertainties in $C_{T}$ and $C_{P}$ and dependency on $J$ itself.
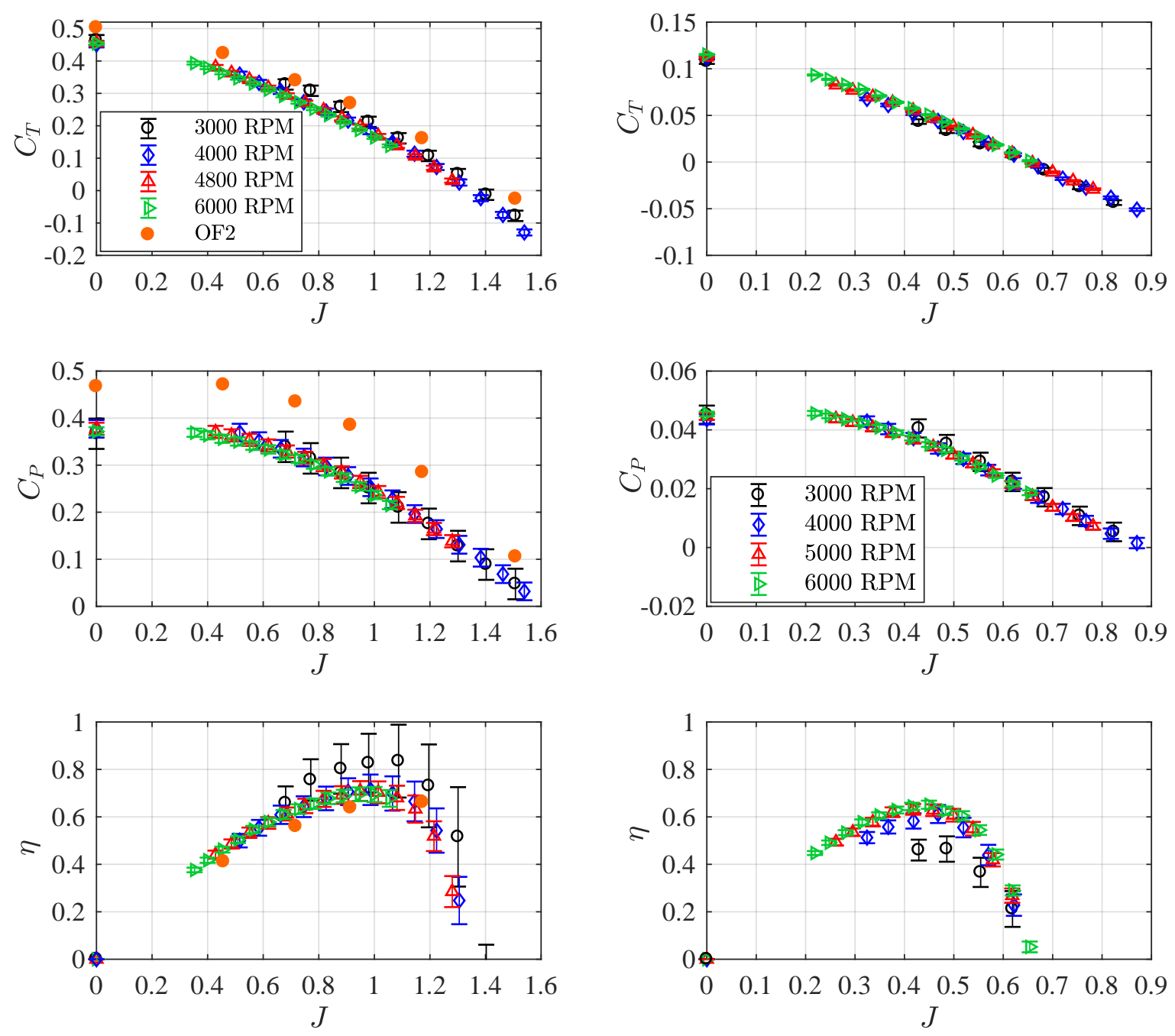

(a) HL Propeller

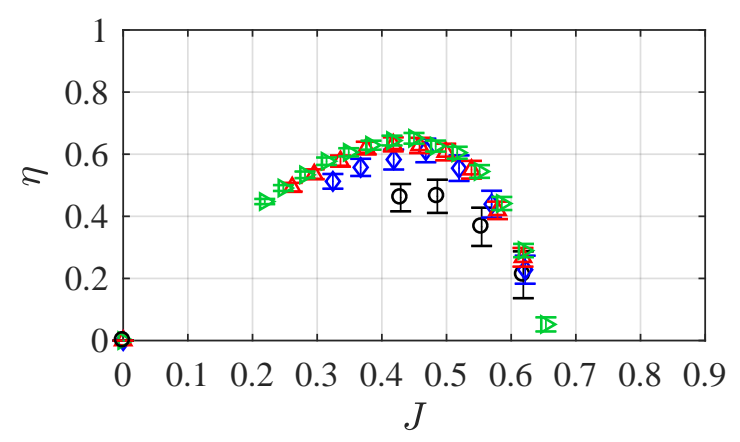

(b) CC Propeller

Figure 8. Measured performance coefficients for the tested propellers. Note: legend entries indicate targeted mechanical rotation rates $\left(\Omega_{m}\right)$. 
As the experimental $C_{T}$ results of the HL propeller show (Fig. 8(a)), there is excellent collapse of the data between the three higher rotation rate cases. However, the cases for which $\Omega_{m}=3000$ RPM display slightly higher thrust values. It is also interesting to note that the CFD predictions for $C_{T}$ match better with this data set, and are seen to overpredict the trends for the other rotation rate data sets. By contrast, the $C_{P}$ trend in the CFD data overpredicts all experimental data sets. Finally, the predicted data for $\eta$ are seen to slightly underpredict the values seen in the experimental data. It is believed that these discrepancies are the result of blade elastic deflections (e.g., blade coning, twisting, etc.), which are in the experimental measurements. The CFD in these cases only accounts for rigid blade rotation, and not for elastic blade deformations. Observations of the tested propeller blades revealed physical cracks near the blade roots that are indicative of blade coning and twisting behavior that would result in a pitch-shallowing effect. This would reduce the effective angles of attack seen by the blades, and therefore, result in reduced blade aerodynamic loading. The CC propeller aerodynamic coefficient trends shown in Fig. 8(b) are slightly different from those of the HL propeller. The peak efficiency of the HL propeller is seen to occur in the vicinity of $J \approx 1$ while that for the CC propeller occurs near $J \approx 0.45$. It is interesting to note that the efficiency profile for the HL propeller is highest for the lowest tested rotation rate (however, with higher measurement uncertainties), while the CC propeller efficiency increases with increasing rotation rate. This latter behavior is very similar to the trends of small propellers documented in Ref. 16, which were attributed to small Reynolds number effects on the propeller performance. While the propellers tested in Ref. 16 are considerably smaller than the $\mathrm{CC}$ propeller tested here, the representative Reynolds numbers tested here still only span a range of $2.33 \times 10^{5} \leq \operatorname{Re}_{c} @ 0.75 R \leq 4.66 \times 10^{5}$.

The data plotted in Fig. 8 represent performance results acquired over a wide range of advance ratio conditions. In addition to these runs, an additional set of HL propeller data was acquired in which both freestream and propeller tip Mach numbers were matched with those of the CFD simulations (see Table 2). The average propeller performance coefficients for these runs are provided in Table 3 with comparisons to the CFD prediction data. Data for cases 1-5 reveal average differences (relative to the experimental data) of approximately $17 \%$ in $C_{T}$ and $35 \%$ in $C_{P}$.

Table 3. Performance coefficient comparisons between experiments and predictions.

\begin{tabular}{|c|c|c|c|c|c|c|}
\hline & \multicolumn{2}{|c|}{$C_{T}$} & \multicolumn{2}{c|}{$C_{P}$} & \multicolumn{2}{c|}{$\eta$} \\
\hline Case \# $^{*}$ & Expt. & CFD & Expt. & CFD & Expt. & CFD \\
\hline 1 & 0.462 & 0.503 & 0.375 & 0.467 & 0 & 0 \\
2 & 0.373 & 0.423 & 0.360 & 0.471 & 0.468 & 0.411 \\
3 & 0.295 & 0.339 & 0.324 & 0.434 & 0.644 & 0.560 \\
4 & 0.218 & 0.269 & 0.270 & 0.385 & 0.732 & 0.638 \\
5 & 0.127 & 0.160 & 0.198 & 0.285 & 0.736 & 0.661 \\
6 & -0.067 & -0.026 & 0.063 & 0.105 & -1.583 & -0.379 \\
\hline
\end{tabular}

* Case conditions defined in Table 2 .

To ensure that the measured propeller performance data are uncorrupted by open-jet shear layer contraction effects, an actuator disk model approach developed in Ref. 17 to account for core flow contraction caused by the propeller is utilized. This method utilizes empty test section core flow contraction and shear layer development measurements to compute an allowable upper propeller performance limit denoted by the quantity $\left(C_{T} / J^{2}\right)_{\max }$ (see Ref. 4 for details). Propeller run conditions that exceed this upper limit are considered to be unsuitable for the facility open-jet, since they may result in a core flow contraction that can corrupt the propeller inflow. A plot of the predicted propeller performance limit of LSAWT along with the measured $\left(C_{T} / J^{2}\right)_{\max }$ values for the two propellers tested in this study are provided in Fig. 9. As the results show, both propellers

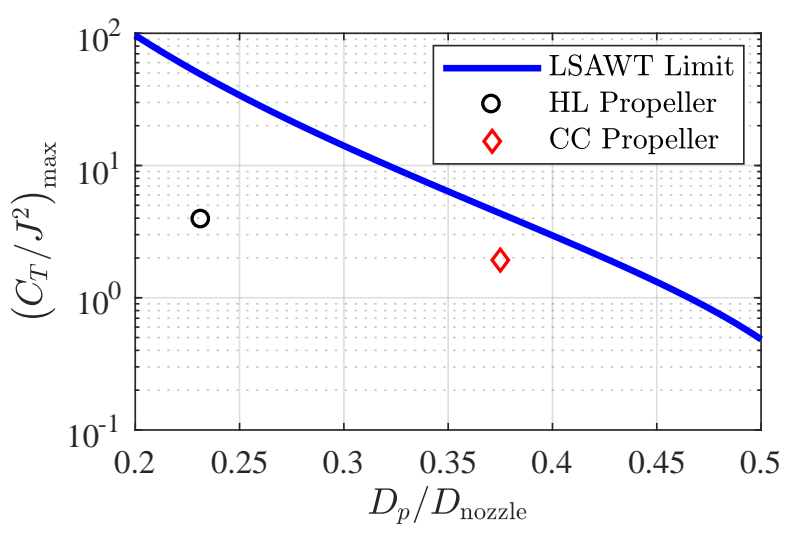

Figure 9. LSAWT propeller operational limits with maximum measured propeller performance conditions. 
fall well below the facility limit; however, the CC propeller comes much closer due to its larger diameter. Furthermore, this is considered to be a conservative estimate since the LSAWT limit was computed using the measured mean core flow size at an axial location of $x / D_{\text {nozzle }}=0.855$ downstream of the inlet trailing edge, while the propeller plane of rotation was located at $x / D_{\text {nozzle }}=0.645$.

\section{B. Propeller Acoustics}

\section{Propeller vs. Facility Noise}

Prior to analyzing the acoustics of the tested propellers, it is important to assess the noise associated with the different testing parameters. More specifically, these include facility flow noise, motor noise, and propeller noise. An assessment of these different noise sources is presented in the form of narrowband acoustic spectra in Fig. 10(a). A total of four different test conditions are shown in this figure, consisting of the different possible combinations of facility, motor rotation, and HL propeller noise. The simplest of these conditions is the case of tunnel freestream flow $\left(M_{\infty}=0.092\right)$ over the static model test stand with no propeller present (black dotted line). This case shows a broadband spectrum, that is essentially identical to the case of an empty test section. ${ }^{4}$ This is useful because it indicates that the noise generated by the static model test stand is negligible compared to the empty facility noise. Furthermore, the case of motor rotation with no propeller $\left(\Omega_{c}=5866 \mathrm{RPM}\right)$ in the absence of flow shows tonal content at harmonics of the rotation rate (that is, at multiples of $100 \mathrm{~Hz}$ ). This case is indicated by the red dash-dotted line. Operation of the motor at the same rotation rate immersed in the tunnel freestream flow (solid green line) shows tonal acoustic content that is very similar to the case with no freestream flow, but with overall higher amplitudes for frequencies above $2 \mathrm{kHz}$. This is believed to be due to air loading on the motor and nacelle system. There is also a slight increase in broadband content in the frequency range of $700 \mathrm{~Hz} \leq f \leq 3 \mathrm{kHz}$ relative to the static MTS in freestream flow, presumably due to turbulent boundary layer flow development along the surface of the rotating spinner. Finally, the propeller test case (solid blue line in Fig. 10(a)) displays a prominent tone at the BPF of $500 \mathrm{~Hz}$, along with subharmonics of 200 and $300 \mathrm{~Hz}$, increased broadband content as compared to the previous cases for frequencies above $500 \mathrm{~Hz}$, and prominent tonal content across a frequency range of $2 \mathrm{kHz} \leq f \leq 7 \mathrm{kHz}$. It is important to note that the majority of this mid-frequency tonal content is shared in common with the previous cases of motor rotation with no propeller present. It is therefore reasonable to conclude that this tonal content is mechanical noise generated by the loaded motor, and not aerodynamic noise caused by the propeller itself. Very similar results were obtained for the CC propeller.



(a) Facility, motor, propeller acoustics

\begin{tabular}{|l|c|c|c|c|}
\hline Parameter & $\cdots$ & $-\cdot-$ & - & - \\
\hline$M_{\infty}=0.092$ & $\checkmark$ & $\boldsymbol{x}$ & $\checkmark$ & $\checkmark$ \\
$\Omega_{m}=6000^{*}$ RPM & $\boldsymbol{x}$ & $\checkmark$ & $\checkmark$ & $\checkmark$ \\
Propeller ON & $\boldsymbol{x}$ & $\boldsymbol{x}$ & $\boldsymbol{x}$ & $\checkmark$ \\
\hline
\end{tabular}

* $\Omega_{c}=5866$ RPM.

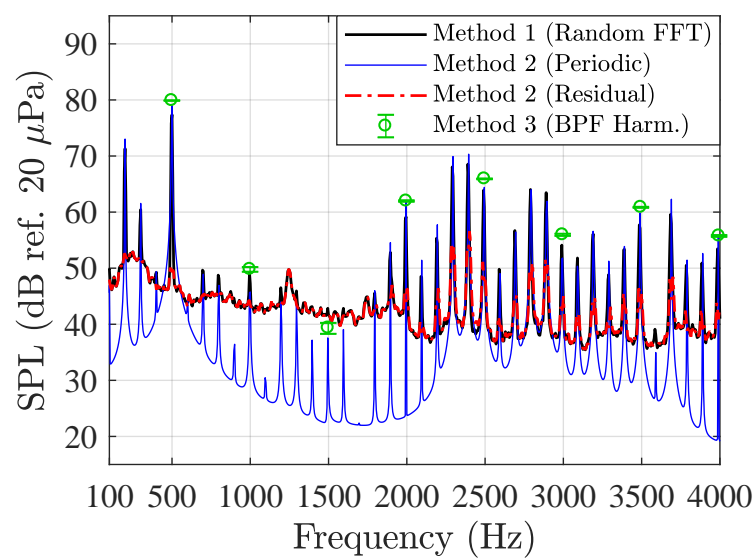

(b) Acoustic processing methods

Figure 10. Illustration of (a) facility, motor, and HL propeller acoustic content, (b) acoustic post-processing methods. (Note: Test conditions represent case 3 in Table 2 at an observer location of $\theta_{o}=90^{\circ}$ ). 
Figure 10(b) provides a spectral overview of the post-processing methods applied to the acoustic data, which were mentioned previously. As the data show, the raw spectrum using method 1 consists of a combination of tonal and broadband content. Method 2 performs reasonably well at dividing the raw spectrum into periodic and residual components, but with some mid-frequency tonal content being retained by the residual spectrum. Method 3 provides the time-averaged BPF harmonic amplitudes, which are computed on a per-revolution basis. The error bars represent the $95 \%$ confidence intervals of the RMS amplitudes. The BPF harmonic amplitudes extracted using this method are then used to compare with the acoustic predictions.

\section{Comparisons with Predictions}

Acoustic prediction comparisons are performed at discrete frequencies (harmonics of the BPF) as a result of the periodic nature of the simulations. As is evidenced in Fig. 10(b), the case of the isolated propeller in a takeoff condition has negligible harmonic content above the 2nd BPF harmonic. This is again under the assumption that the observed tonal content in the mid-frequency range is due to the motor and/or speed controller. Figure 11 provides directivity comparisons of the first and second BPF harmonics between LSAWT measurements and OF2-PSW and PAS predictions. The data of Fig. 11(a) show excellent agreement

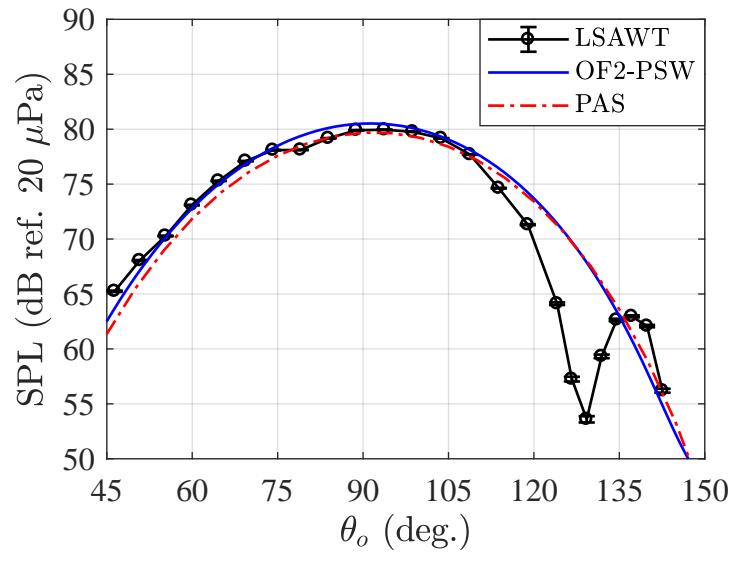

(a) $\mathrm{BPF}_{c}=488 \mathrm{~Hz}$

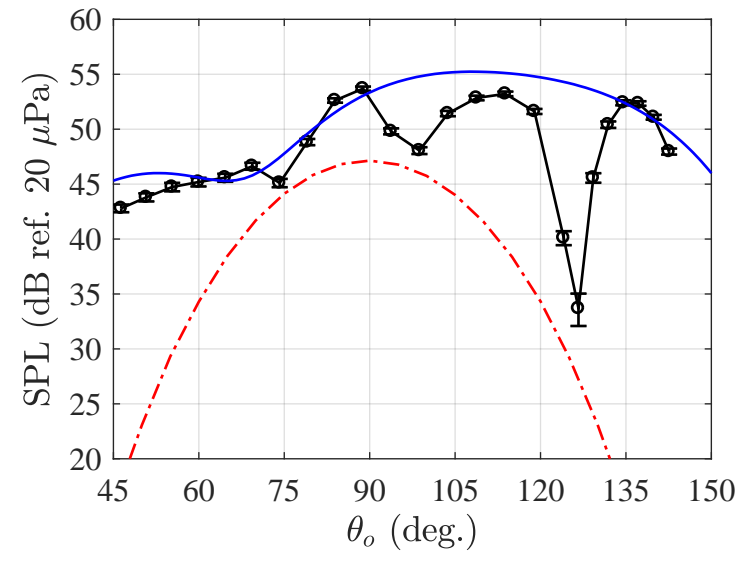

(b) $2 * \mathrm{BPF}_{c}=976 \mathrm{~Hz}$

Figure 11. Directivity comparisons of first and second BPF harmonics between LSAWT experiment and OF2PSW predictions. (Note: flight conditions of case 3 in Table 2; cylindrical shear layer corrections of Ref. 18 applied to LSAWT microphone data)

across an observer angle range of $45^{\circ} \leq \theta_{o} \leq 110^{\circ}$, after which there is a considerable discrepancy associated with a drastic decrease in measured SPL that is not observed in the predictions. An amplitude recovery is then observed at $\theta_{o} \approx 135^{\circ}$. This directivity null behavior is observed across the same observer angle range for the second BPF harmonic in Fig. 11(b). Furthermore, while the OF2-PSW predictions of the second BPF harmonic shows an overall trend agreement with the experimental data, the PAS prediction does not. Possible explanations for this disagreement are discussed in the following section.

Figure 12 provides a comparison between LSAWT measurements and OF2-PSW predictions of the BPF directivity for the HL propeller for cases of different propeller tip speed and advance ratio (cases 4-6 in Table 2). As these results show, there is overall reasonable agreement in terms of directivity trends between the data sets. It is also interesting to note the appearance of a directivity null in the prediction of case 5 in Fig. 12(b), which is similar to that shown in Fig. 12(a), however at a different observer angle. The experimental results for case 6 , however, show a directivity null in the vicinity of $\theta_{C} \approx 100^{\circ}$, whereas this is not present in the prediction. The causes of these directivity nulls may be explained by a breakdown of the noise source contributions in the prediction data. This is done in Fig. 12(c) for case 5. As this plot shows, the directivity null near $\theta_{C} \approx 130^{\circ}$ is the result of destructive interference between the thickness and loading noise source terms. It is reasonable to assume that the occurrence of the directivity nulls in the measured data at different observer angles than the prediction data might be explained by the considerable over-prediction of aerodynamic loads discussed in the previous section. The following section discusses how 
the possibility of blade-to-blade variations in the tested propeller could be a possible culprit in the observed discrepancies.

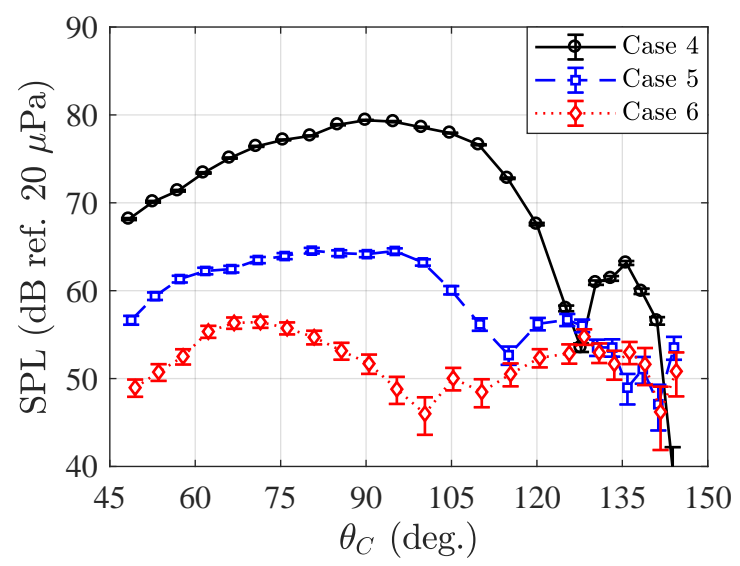

(a) LSAWT measurements

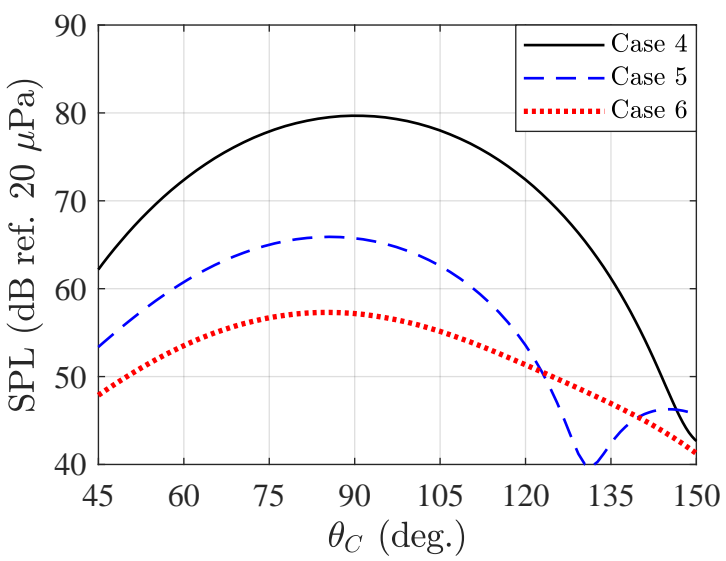

(b) OF2-PSW predictions

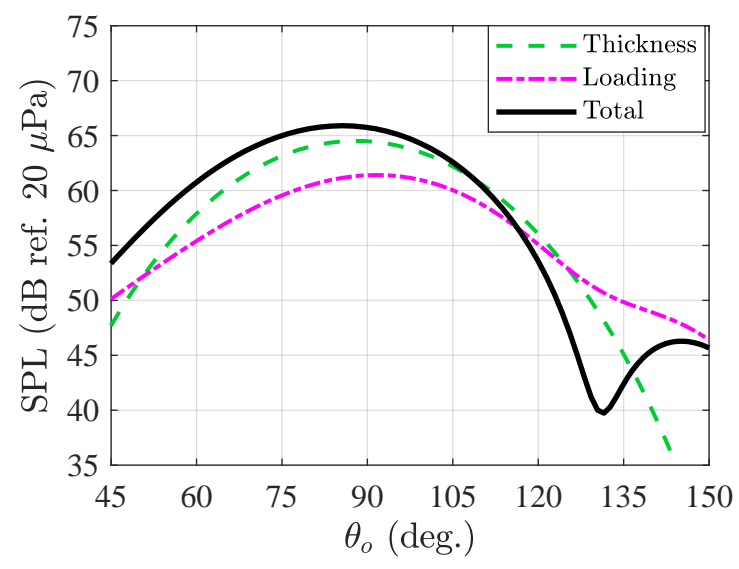

(c) Noise source term breakdown for case 5 (OF2-PSW)

Figure 12. HL propeller directivity comparisons of first BPF harmonic for cases of different propeller tip speeds and advance ratios. (Note: flight conditions listed in Table 2)

\section{Investigation of Observed Discrepancies}

Discrepancies between experimental measurements and predictions discussed in the previous two sections pertain to both aerodynamic and acoustic quantities. While it is very difficult to identify the exact causes of these differences, some initial investigations are performed here. PAS is an excellent tool for performing parametric analyses with relatively fast computation times as compared to CFD. In the previous section, PAS acoustic prediction of the second BPF harmonic of the HL propeller was seen to be in considerable disagreement with both the OF2-PSW prediction and LSAWT measurement. The CC propeller offers an excellent opportunity to determine if this disagreement is related to the unconventional geometry of the HL propeller or a more fundamental issue in relating the prediction to the wind tunnel measurement. Figure 13 presents comparisons of the first and second BPF harmonics between LSAWT measurements and PAS predictions of the CC propeller at different advance ratios. As these results show, PAS performs very well at capturing the change in directivity trends with increasing propeller tip speed for both BPF harmonics. While there are some discrepancies in the first BPF harmonic for both advance ratio cases, this is believed to be due to slight inaccuracies in the mechanical measurement process of the blade profile used to generate the PAS blade element grid. Overall, however, PAS is seen to perform very well at predicting the acoustics of the $\mathrm{CC}$ propeller for different advance ratios. It is reasonable to assume that the discrepancies between PAS and the HL propeller are likely due to physical phenomena not accounted for in the prediction method 
(such as flow in the blade radial direction not accounted for in the BEMT methodology) and/or physical inconsistencies between the tested and simulated propeller blade geometries.

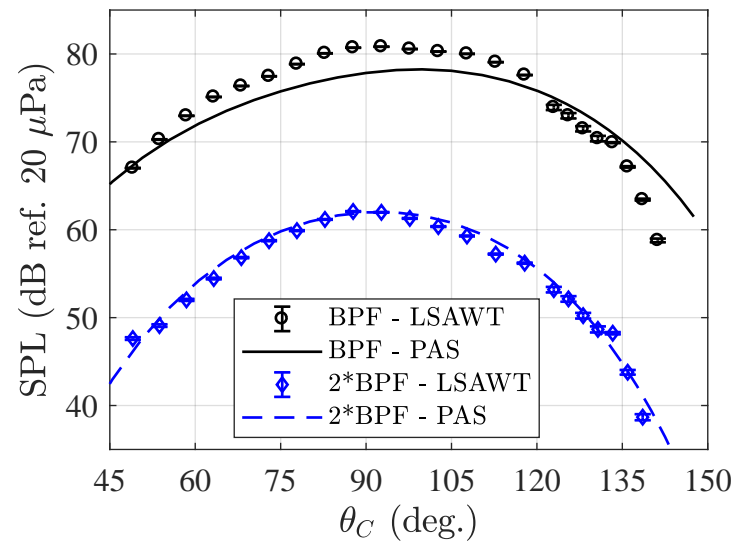

(a) $\Omega_{m}=4000 \mathrm{RPM}, J=0.468$

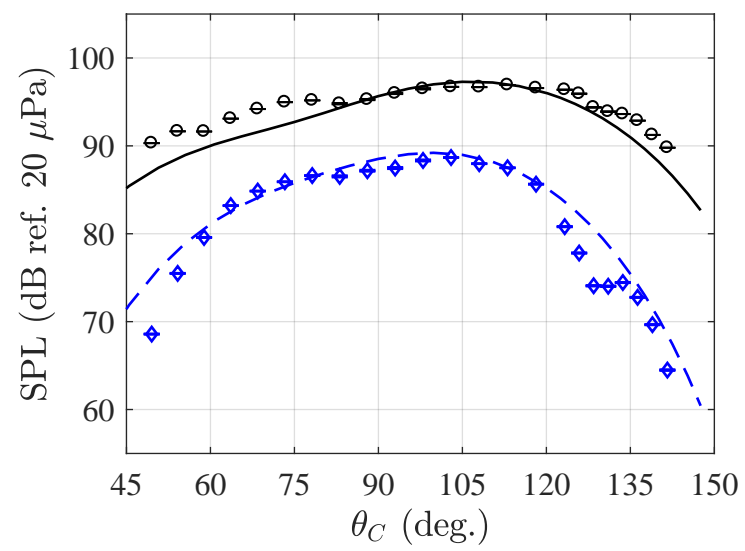

(b) $\Omega_{m}=6000 \mathrm{RPM}, J=0.349$

Figure 13. Directivity comparisons of first and second BPF harmonics between LSAWT experiment and PAS predictions for the $\mathrm{CC}$ propeller at different advance ratios.

One of the suspected causes of both the aerodynamic and acoustic discrepancies between the HL propeller measurements and predictions is blade deflections. More specifically, it is believed that the individual HL propeller blades deflect uniquely relative to each other. As was shown in Fig. 10(a), the HL propeller spectra exhibit prominent acoustic tones at shaft order harmonics less than the BPF. This is indicative of blade imbalance effects. Further evidence of this behavior can be found by observation of periodically averaged acoustic time histories, an example of which is provided in Fig. 14(a) for a microphone located in the plane of the HL propeller. This figure clearly shows a considerable amount of variation from one blade passage to the next. For reference, Fig. 14(b) provides a similar plot for the CC propeller for the run condition shown previously in Fig. 13(a). There is very little discernible difference for this propeller from one blade passage to the next. Additionally, the standard deviation of the periodically averaged microphone measurement (visualized as $\bar{p} \pm \sigma$ in Fig. 14) for the HL propeller is seen to be much higher than that for the CC propeller. These results indicate that the CC propeller is much better balanced than the HL propeller.

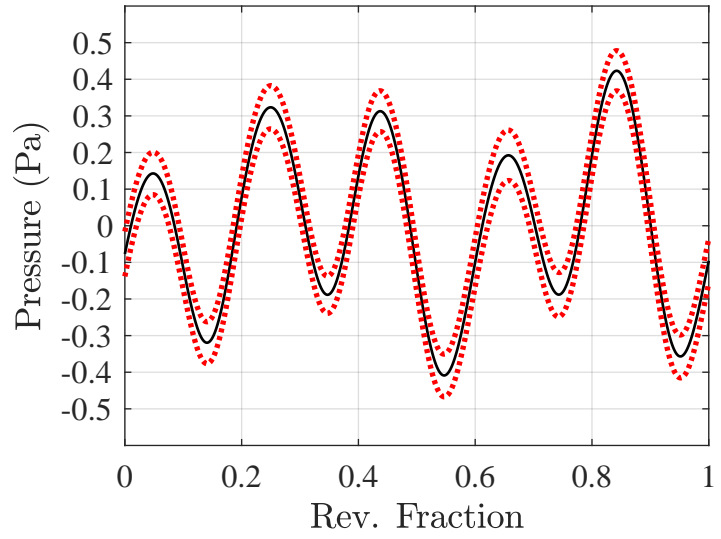

(a) HL Propeller, Case 3

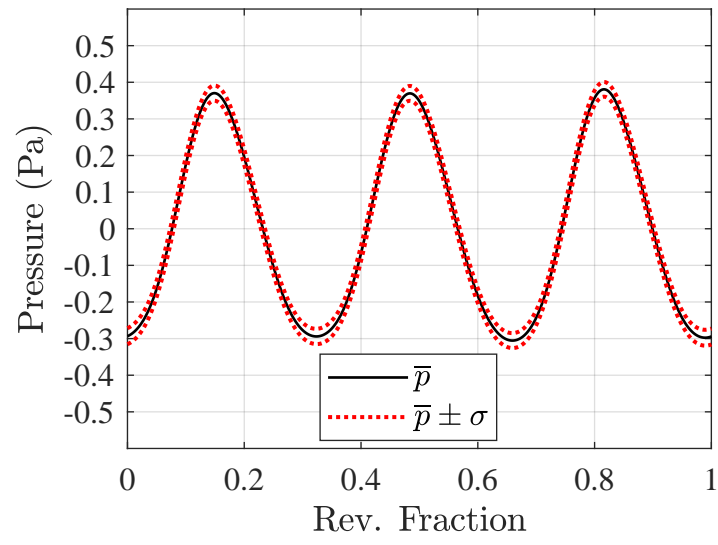

(b) CC Propeller, $J=0.468$

Figure 14. Periodically averaged acoustic time histories measured in the propeller plane $\left(\theta_{o}=90^{\circ}\right)$ for representative cases of HL and CC propellers. Time histories are constructed using the first ten shaft orders.

It is believed that the physical HL propeller blades undergo dynamic deflections as they rotate about the motor hub. While it is very difficult to model this computationally, the PAS tool can still be utilized to simulate the effects of blade-to-blade geometric inconsistencies in a steady sense. An additional challenge 
with simulating this behavior relates to which physical geometric properties of the blade are the most likely culprit(s) to explain the observed phenomenon. The blades can deflect in a number of ways; these include azimuthal lagging, coning, and blade shallowing (untwisting). Illustrations of these types of deflections are provided in Fig. 15. These images were generated using the Improved Blade Shape (IBS) module of PAS. ${ }^{13}$ Due to the large number of possible amounts and combinations of these deflections that can be simulated, only blade shallowing is considered here.

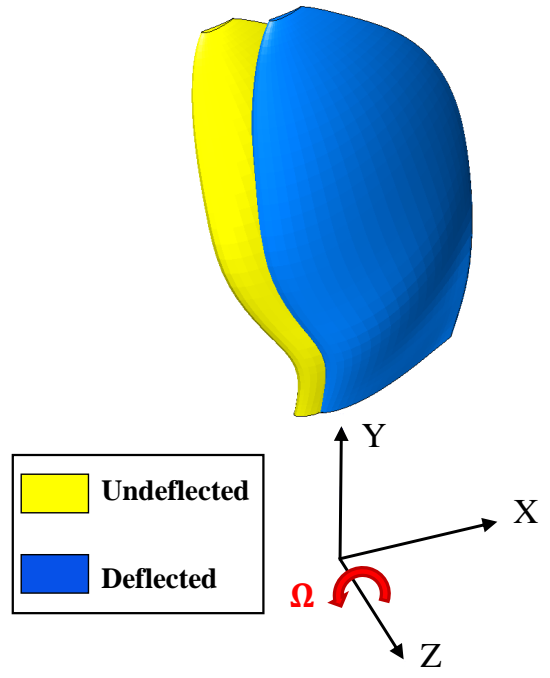

(a) Blade Lagging

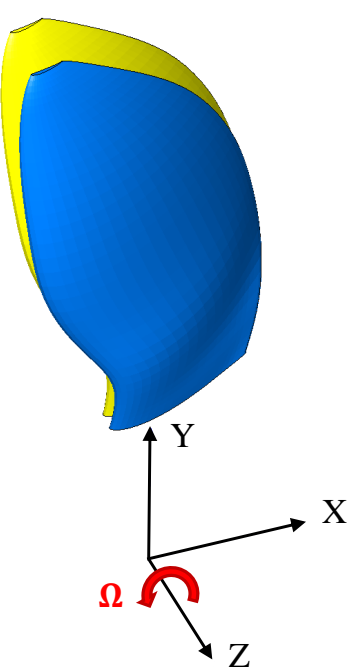

(b) Blade Coning

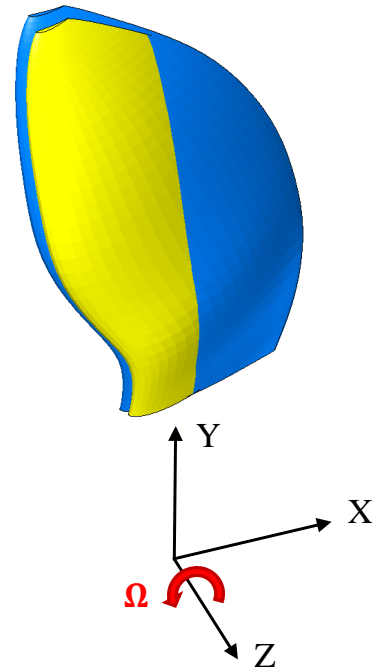

(c) Blade Shallowing

Figure 15. Illustrations of possible types of blade deflections under loading. Note: PAS coordinate system indicated; $\mathrm{Z}$ axis represents forward flight direction.

The PAS results for the HL propeller shown thus far were computed using a collective twist modification of $\Delta \beta=-5^{\circ}$ relative to the original computational blade geometry. This is an example of blade shallowing, which is visually depicted in Fig. 15(c). This collective setting was originally implemented in Ref. 19 for the purpose of better matching of predicted thrust values between PAS and CFD results for a simulated takeoff condition (case 3 in Table 2). To obtain an initial estimate of the effects of blade-to-blade variation, PAS is used to superimpose the cases of individual blade passages for a set of geometrically modified blade shapes. This is done by computing the surface pressure loading on a blade in PAS for each blade deflection condition, then importing this data into the PSU-WOPWOP code. The resulting PAS-PSW acoustic time history predictions of the HL propeller is provided in Fig. 16. This figure shows the acoustic predictions for the cases of equal collective twist modification for all blades $\left(\Delta \beta=-5^{\circ}\right)$ and for a blade-to-blade collective twist variation of $\Delta \beta=\left\{-4^{\circ},-5^{\circ},-6^{\circ},-4^{\circ},-5^{\circ}\right\}$. Note that this set of collective twist perturbations was selected such that the average of these values is close to the original case of equal collective twist modification. This is important since it is assumed that both of these cases represent comparable aerodynamic load generation. As expected, the acoustic time history for the case of consistent blade shallowing between all five blades $\left(\Delta \beta=-5^{\circ}\right)$ results in blade passage events of identical amplitude. Perturbation of this collective blade setting by $\pm 1^{\circ}$ results in variation of the amplitudes of these blade passage events by as much as $59 \%$ relative to the equal collective case. It is also interesting to observe the qualitative similarities between this prediction case and the experimental measurements for the same flight condition in Fig. 14(a). It is important to note, however, that this PAS prediction case does not accurately predict the type of frequency null behavior observed in the BPF directivity plots of Fig. 12(a). This is again believed to be related to the idea that the experimental blades are undergoing a time-varying deflection as they rotate about the motor hub. Despite this inconsistency, these preliminary PAS predictions provide initial proof that experimental blade deflections are a likely culprit of the observed aerodynamic performance and acoustic discrepancies between measurements and predictions of the tested HL propeller. 


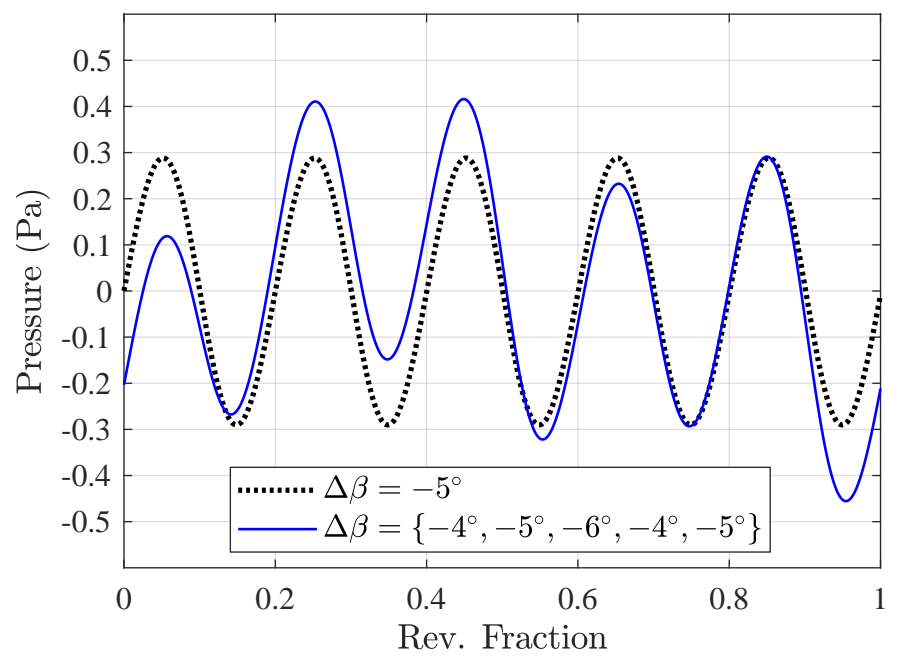

Figure 16. PAS total acoustic time history predictions of the HL propeller in the propeller plane $\left(\theta_{o}=90^{\circ}\right)$ subjected to uniform and variable blade shallowing.

\section{Conclusions and Future Work}

This study assesses the aerodynamic performance and acoustic characteristics of a high-lift propeller concept for DEP vehicle applications. Tests were also conducted on a more conventional propeller geometry for fixed-wing cruise applications for reference. A combination of experimental and computational prediction efforts are made, with an emphasis on validation of the prediction results and capabilities. Both highand low-fidelity prediction techniques are implemented, encompassing CFD-based and blade element-based acoustic prediction methods. CFD predictions of the high-lift propeller revealed agreement in aerodynamic performance trends with the experiment, however, with considerable overprediction in coefficient values. Similarly, CFD-based acoustic predictions of HL propeller BPF directivity trended well with experimental measurements for different advance ratios. However, experimental measurements display the presence of directivity nulls for aft observer angles that differ from the prediction data. Furthermore, acoustic predictions using PAS show reasonable agreement with experimental measurements of the BPF directivity, however, exhibit considerable discrepancies for the next higher harmonic. The ability of PAS to accurately predict the experimentally measured tonal directivities for the conventional propeller design is a possible indicator that the HL propeller geometry may exhibit a more complex flow field than can be accurately modeled by PAS. Preliminary investigation as to the possible causes of predicted discrepancies was conducted by applying geometric perturbations to the PAS blade grid on a per-blade basis. Predicted propeller revolution acoustic time histories show qualitative agreement with the experimental measurements. While this does not accurately identify the actual modified experimental blade geometry, it does provide evidence that unique blade deflections are a possible explanation for the observed prediction discrepancies.

Future work will include testing of a newly designed high-lift propeller concept in both multipropeller and propeller-wing configurations. The purpose of these tests will be to identify more complex flow and acoustic phenomena associated with these types of propellers in a semi-installed configuration. Assessment of reflections and scattering present within the LSAWT will also be performed using a time-domain acoustic scattering prediction code. ${ }^{20}$ This will be an important assessment due to the increased presence of reflective surfaces for multipropeller and propeller-wing tunnel configurations.

\section{Acknowledgments}

The authors would like to acknowledge Mr. John Swartzbaugh, Mr. Stanley Mason, Mr. Jeffrey Collins, and Mr. Bryan Lamb of the Low Speed Aeroacoustic Wind Tunnel at NASA Langley Research Center for their tireless efforts involving test setup, tunnel operation, and data acquisition. The authors would also like to acknowledge Dr. Pieter Buning of the Computational Aerosciences Branch at NASA Langley for providing propeller CFD prediction data. Finally, the authors acknowledge Ms. Nicole Pettingill of the Aeroacoustics 
Branch at NASA Langley for performing physical blade geometry measurements used for blade element analysis. Funding for this work is being provided by the NASA Transformative Tools and Technologies (TTT) project, which is part of NASA's Transformative Aeronautics Concepts Program (TACP).

\section{References}

${ }^{1}$ Warwick, G., "NASA's Electric-Propulsion Wing Test Helps Shape Next X-Plane," Aviation Week EJ Space Technology, Vol. 24, 2015.

${ }^{2}$ Borer, N. K., Patterson, M. D., Viken, J. K., Moore, M. D., Bevirt, J., Stoll, A. M., and Gibson, A. R., "Design and Performance of the NASA SCEPTOR Distributed Electric Propulsion Flight Demonstrator," 16th AIAA Aviation Technology, Integration, and Operations Conference, Washington, D.C., 2016, AIAA Paper 2016-3920.

${ }^{3}$ Patterson, M. D., Derlaga, J. M., and Borer, N. K., "High-Lift Propeller System Configuration Selection for NASA's SCEPTOR Distributed Electric Propulsion Flight Demonstrator," 16th AIAA Aviation Technology, Integration, and Operations Conference, AIAA, Washington, D.C., 2016, AIAA Paper 2016-3922.

${ }^{4}$ Zawodny, N. S. and Haskin, H. H., "Small Propeller and Rotor Testing Capabilities of the NASA Langley Low Speed Aeroacoustic Wind Tunnel," 23rd AIAA/CEAS Aeroacoustics Conference, AIAA, Denver, CO, 2017, AIAA Paper $2017-3709$.

${ }^{5}$ Stoll, A. M., Bevirt, J., Moore, M. D., Fredericks, W. J., and Borer, N. K., "Drag reduction through distributed electric propulsion," 14th AIAA Aviation Technology, Integration, and Operations Conference, AIAA, Atlanta, GA, 2014, AIAA Paper 2014-2851.

${ }^{6}$ Stoll, A. M., "Comparison of CFD and Experimental Results of the LEAPTech Distributed Electric Propulsion Blown Wing," 15th AIAA Aviation Technology, Integration, and Operations Conference, AIAA, Dallas, TX, 2015, AIAA Paper 2015-3188.

${ }^{7}$ Zawodny, N. S., Boyd Jr., D. D., and Burley, C. L., "Acoustic Characterization and Prediction of Representative, SmallScale Rotary-Wing Unmanned Aircraft System Components," AHS International 72nd Annual Forum, American Helicopter Society, West Palm Beach, FL, 2016.

${ }^{8}$ Zawodny, N. S. and Boyd Jr., D. D., "Investigation of Rotor-Airframe Interaction Noise Associated with Small-Scale Rotary-Wing Unmanned Aircraft Systems," AHS International 73rd Annual Forum, American Helicopter Society, Fort Worth, TX, 2017.

${ }^{9}$ Bendat, J. S. and Piersol, A. G., Random Data Analysis and Measurement Procedures, chap. 6: Statistical Errors in Advanced Estimates, John Wiley \& Sons Inc., 3rd ed., 2000, pp. 316-348.

${ }^{10}$ Nichols, R. H., Tramel, R. W., and Buning, P. G., "Evaluation of Two High-Order Weighted Essentially Nonoscillatory Schemes," AIAA Journal, Vol. 46, No. 12, June 2008, pp. 3090-3102.

${ }^{11}$ Brentner, K. and Farassat, F., "Modeling aerodynamically generated sound of helicopter rotors," Progress in Aerospace Sciences, Vol. 39, April 2003, pp. 83-120.

${ }^{12}$ Nark, D. M., Buning, P. G., Jones, W. T., and Derlaga, J. M., "High-Lift Propeller Noise Prediction for a Distributed Electric Propulsion Flight Demonstrator," 23rd AIAA/CEAS Aeroacoustics Conference, AIAA, Denver, CO, 2017, AIAA Paper 2017-3713.

${ }^{13}$ Nguyen, L. C. and Kelly, J. J., A Users Guide for the NASA ANOPP Propeller Analysis System, Hampton, VA, 1997, NASA CR 4768

${ }^{14}$ Farassat, F., "Linear Acoustic Formulas for Calculation of Rotating Blade Noise," AIAA Journal, Vol. 19, No. 9, Sep 1981, pp. 1122-1130.

${ }^{15}$ Farassat, F., Derivation of Formulations 1 and $1 A$ of Farassat, Hampton, VA, 2007, NASA TM 2007-214853.

${ }^{16}$ Deters, R. W., Ananda, G. K., and Selig, M. S., "Reynolds Number Effects on the Performance of Small-Scale Propellers," 32nd AIAA Applied Aerodynamics Conference, AIAA, Atlanta, GA, 2014, AIAA Paper 2014-2151.

${ }^{17}$ Block, P. J. W., Operational Evaluation of a Propeller Test Stand in the Quiet Flow Facility at Langley Research Center, Hampton, VA, 1982, NASA TM 84523.

${ }^{18}$ Amiet, R. K., "Refraction of Sound by a Shear Layer," Journal of Sound and Vibration, Vol. 58, No. 4, 1978, pp. 467-482.

${ }^{19}$ Nark, D. M., Jones, W. T., Boyd, D. D., and Zawodny, N. S., "Isolated Open Rotor Noise Prediction Assessment Using the F31A31 Historical Blade Set," 54th AIAA Aerospace Sciences Meeting, AIAA, San Diego, CA, 2016, AIAA Paper $2016-1271$.

${ }^{20} \mathrm{Hu}$, F. Q., Pizzo, M. E., and Nark, D. M., "On the Assessment of Acoustic Scattering and Shielding by Time Domain Boundary Integral Equation Solutions," 22nd AIAA/CEAS Aeroacoustics Conference, AIAA, Lyon, France, 2016, AIAA Paper 2016-2779. 